\title{
Prospective cohort study of patients with advanced cancer and their relatives on the experienced quality of care and life (eQuiPe study): a study protocol
}

Janneke van Roij ${ }^{1,2,3,4^{*}}$ (D) Myrte Zijlstra ${ }^{1,3,5}$, Laurien Ham ${ }^{1,3}$, Linda Brom ${ }^{1,3}$, Heidi Fransen ${ }^{1,3}$, Art Vreugdenhil ${ }^{6}$, Natasja Raijmakers ${ }^{1,3}$, Lonneke van de Poll-Franse ${ }^{1,2,7}$ and eQuiPe study group

\begin{abstract}
Background: Palliative care is becoming increasingly important because the number of patients with an incurable disease is growing and their survival is improving. Previous research tells us that early palliative care has the potential to improve quality of life (QoL) in patients with advanced cancer and their relatives. According to limited research on palliative care in the Netherlands, patients with advanced cancer and their relatives find current palliative care suboptimal. The aim of the eQuiPe study is to understand the experienced quality of care (QoC) and QoL of patients with advanced cancer and their relatives to further improve palliative care.

Methods: A prospective longitudinal observational cohort study is conducted among patients with advanced cancer and their relatives. Patients and relatives receive a questionnaire every 3 months regarding experienced QoC and QoL during the palliative trajectory. Bereaved relatives receive a final questionnaire 3 to 6 months after the patients' death. Data from questionnaires are linked with detailed clinical data from the Netherlands Cancer Registry (NCR). By means of descriptive statistics we will examine the experienced QoC and QoL in our study population. Differences between subgroups and changes over time will be assessed while adjusting for confounding factors.

Discussion: This study will be the first to prospectively and longitudinally explore experienced QoC and QoL in patients with advanced cancer and their relatives simultaneously. This study will provide us with population-based information in patients with advanced cancer and their relatives including changes over time. Results from the study will inform us on how to further improve palliative care.
\end{abstract}

Trial registration: Trial NL6408 (NTR6584). Registered in Netherlands Trial Register on June 30, 2017.

Keywords: Study protocol, Prospective study, Longitudinal cohort study, Quality of care, Quality of life, Palliative care, Advanced cancer, Relatives

\footnotetext{
* Correspondence: j.vanroij@iknl.nl

${ }^{1}$ The Netherlands Comprehensive Cancer Organization, PO Box 19079, 3501 DB Utrecht, The Netherlands

${ }^{2}$ CoRPS - Center of Research on Psychology in Somatic Diseases, Department

of Medical and Clinical Psychology, Tilburg University, Tilburg, The Netherlands

Full list of author information is available at the end of the article
}

(c) The Author(s). 2020 Open Access This article is licensed under a Creative Commons Attribution 4.0 International License, which permits use, sharing, adaptation, distribution and reproduction in any medium or format, as long as you give appropriate credit to the original author(s) and the source, provide a link to the Creative Commons licence, and indicate if changes were made. The images or other third party material in this article are included in the article's Creative Commons licence, unless indicated otherwise in a credit line to the material. If material is not included in the article's Creative Commons licence and your intended use is not permitted by statutory regulation or exceeds the permitted use, you will need to obtain permission directly from the copyright holder. To view a copy of this licence, visit http://creativecommons.org/licenses/by/4.0/ The Creative Commons Public Domain Dedication waiver (http://creativecommons.org/publicdomain/zero/1.0/) applies to the data made available in this article, unless otherwise stated in a credit line to the data. 


\section{Background}

Death comes to us all. In 2017, almost 47.000 people died of cancer in the Netherlands, which was with $31 \%$ the most common cause of death, followed by cardiovascular disease (25\%) and mental disorders or diseases of the nervous system (14\%) [1]. The number of people who die of cancer is relatively stable over time [2], despite increasing incidence of cancer and new treatment modalities in cancer, such as immunotherapies and targeted therapies. Fortunately, early detection and advances in cancer treatments have greatly improved survival. Consequently, the time patients live after their diagnosis of advanced cancer is prolonged and the number of patients diagnosed with advanced cancer has increased.

The disease trajectory of advanced cancer for patients is often depicted as a chronic illness, eventually followed by a steep decline and an inevitable death [3]. For relatives of patients with advanced cancer, the disease trajectory also includes a bereavement period after the death of a loved one. At some point in the advanced cancer trajectory, palliative care becomes important. Palliative care is an approach that provides prevention and relief of suffering by means of early identification and assessment and treatment of pain and other physical, psychosocial and spiritual problems [4]. Ideally, palliative care is timely and gradually integrated in oncological care so patients and relatives benefit most from palliative care services [3]. It is important that palliative care is timely integrated in standard oncological care because quality of life (QoL) is improved when patients with advanced cancer receive early palliative care [5-8].

Despite rapid developments [9], the integration and quality of palliative care in oncological care in the Netherlands could be further improved. Recent research shows that patients with advanced cancer are only reasonably satisfied with hospital care $[10,11]$. This is worrisome, as the study by Engel et al. suggests that the experienced quality of care $(\mathrm{QoC})$ and QoL may be positively associated. The effect evaluation of the Dutch National Quality Improvement Program Palliative Care showed that most patients and relatives are satisfied with palliative care, but improvements regarding psychosocial and spiritual support and post-bereavement care for relatives are needed [12]. Other research among relatives of patients who died in a University hospital showed that bereaved relatives reported a broad range of experiences, which suggest a widespread variance of the QoC [13]. For instance, Witkamp et al. showed that only $64 \%$ of bereaved relatives reported that they had been told that the patient's death was imminent and 53\% stated that the patients' symptoms and problems in the last $24 \mathrm{~h}$ had been sufficiently alleviated. The same study found that according to bereaved relatives, only $42 \%$ of the patients had been sufficiently involved in medical decision making [13]. Unfortunately, solid and conclusive information on the experienced QoC and QoL in patients with advanced cancer and their relatives is scarce. Moreover, longitudinal research during the advanced cancer trajectory in patients and relatives is lacking.

A prospective longitudinal observational cohort study on experienced QoC and QoL in patients with advanced cancer and their relatives in the Netherlands is needed. This study will provide more insight into the care experiences, needs and QoL of patients with advanced cancer and their relatives that can guide us in improving daily oncological care and the integration of palliative care.

\section{Methods \\ Aim}

The aim of this study is to gain insight into the care experiences and QoL of patients with advanced cancer and their relatives. The following research questions will be addressed:

- What is the experienced QoC according to patients with advanced cancer and their relatives?

- What is the experienced QoL in patients with advanced cancer and their relatives?

- Which factors are associated with the experienced QoC and QoL in patients with advanced cancer and their relatives?

\section{Study design}

The study is a prospective longitudinal observational cohort study on experienced QoC and QoL in patients with advanced cancer and their relatives (eQuiPe study). Patients and their relatives are invited to complete questionnaires on experienced QoC and QoL every 3 months until death. Three to 6 months after a patient is deceased, the bereaved relative will receive a short final questionnaire. The survey data will be directly linked to the detailed clinical data routinely collected on patient characteristics, tumour characteristics, and treatment from the Netherlands Cancer Registry (NCR).

\section{Setting}

The eQuiPe study is a nationwide study that is conducted in multiple hospitals $(n=40)$ in the Netherlands. Per hospital, the departments of medical oncology, pulmonology, and/or urology are participating in the study to identify eligible patients between November 2017 and January 2020.

\section{Study population}

All patients with a diagnosis of a solid metastasized tumor (stage IV) are eligible for inclusion. Additional inclusion criteria are required for patients diagnosed with breast cancer and with prostate cancer to reduce 
variation and overrepresentation of patients with advanced cancer with a relatively good prognosis. Patients diagnosed with breast cancer are eligible when their metastases are located in multiple organ systems. Patients suffering from prostate cancer are eligible when their cancer is metastasized and castrate-resistant. These criteria are based on information regarding the mean survival time of these groups (NCR). Relatives of included patients, as chosen by the patient, will also be invited to participate in the study. Patients or relatives can participate in the study irrespective of the participation of the other. Patients are also allowed to invite more than one relative to participate in the study. Table 1 provides an overview of the inclusion and exclusion criteria.

\section{Recruitment}

Health care professionals of participating hospitals will identify patients who meet the inclusion and exclusion criteria. Health care professionals will hand out a patient information leaflet and ask eligible patients if they may be approached by the research team. The patient information leaflet will include comprehensive and understandable information regarding the study. Health care professionals will hand over the patients' name and phone number to the

Table 1 Inclusion- and exclusion criteria

\begin{tabular}{|c|c|}
\hline \multicolumn{2}{|l|}{ Inclusion criteria: } \\
\hline $\begin{array}{l}\text { Patients are eligible for inclusion } \\
\text { if they are; }\end{array}$ & $\begin{array}{l}\text { - diagnosed with (progression of) } \\
\text { a solid tumour (stage IV) with } \\
\text { metastases } \\
\text { - additional criteria are in place for } \\
\text { the following diagnosis: } \\
\text { - breast cancer (stage IV with } \\
\text { metastases in multiple organ } \\
\text { systems) } \\
\text { - prostate cancer (stage IV and } \\
\text { Castrate-Resistant) } \\
\text { - older than } 18 \text { years } \\
\text { - able to complete a Dutch self- } \\
\text { report questionnaire } \\
\text { - able to understand the objective } \\
\text { of the study and have signed the } \\
\text { informed consent }\end{array}$ \\
\hline $\begin{array}{l}\text { Relatives of patients are eligible } \\
\text { for inclusion if they are; }\end{array}$ & $\begin{array}{l}\text { - indicated by the patient as } \\
\text { relative } \\
\text { - older than } 18 \text { years } \\
\text { - able to complete a Dutch self- } \\
\text { report questionnaire } \\
\text { - able to understand the objective } \\
\text { of the study and have signed the } \\
\text { informed consent }\end{array}$ \\
\hline \multicolumn{2}{|l|}{ Exclusion criteria: } \\
\hline $\begin{array}{l}\text { Patients and their relatives are } \\
\text { excluded for participation in } \\
\text { the study if; }\end{array}$ & $\begin{array}{l}\text { - they suffer from dementia } \\
\text { - they have a history of severe } \\
\text { psychiatric illness }\end{array}$ \\
\hline
\end{tabular}

research team after receiving consent from the patient, which is noted in the patient file or noted on a research sheet. These contact details will be given by phone, secured email or an online secured shared document, whichever route is preferred by the hospital. There is a possibility of self-referral for patients with advanced cancer and their relatives. Advertisement is spread via a Dutch online platform for patients and relatives who are confronted with cancer (www.kanker.nl). Patients and relatives can leave a contact request for the researcher. The recruitment procedure is similar for patients referred by their health care professional.

\section{Study procedures Inclusion}

A flowchart of the study procedures are presented in Fig. 1. Within a few days after receiving the patient's contact information a researcher will phone the patient to explain the study and discuss participation. The patient is asked whether the researcher may approach one of his/her relatives. The relative is informed about the study via a similar procedure. When the patient and/ or relative are willing to participate in the study, they are given the option to choose for the informed consent and questionnaires on paper or a web-based version via the Patient Reported Outcomes Following Initial treatment and Long-term Evaluation of Survivorship (PROFILES) registry [14].

\section{Data collection}

For the web-based version: after giving consent, participants will receive a letter that contains a link to a secure website (www.profielstudie.nl) where the patient can complete the web survey with their own login codes. The login codes are not directly linked to the patient. Patients who complete the online questionnaire can stop and save their data at each desired moment so they can continue the questionnaire at another time. If the participant prefers a paper version of the survey, they receive a paper version with a stamped self-addressed envelope to return the questionnaire to the researcher. If patients do not complete their questionnaire within 2 weeks, a reminder via email or letter will be sent, including the questionnaire. If the patient does not complete their questionnaire within 2 weeks after the reminder, they will be contacted by phone. A questionnaire regarding QoC and QoL will be sent in the same manner every 3 months, till participants indicate that they no longer want to participate in the study, or until death. After the death of a patient, the participating relative will receive our condolences by a personal postcard. Three to 6 months after the death of the patient, the participating bereaved relative will receive a final request to complete the last questionnaire regarding his or her experiences 


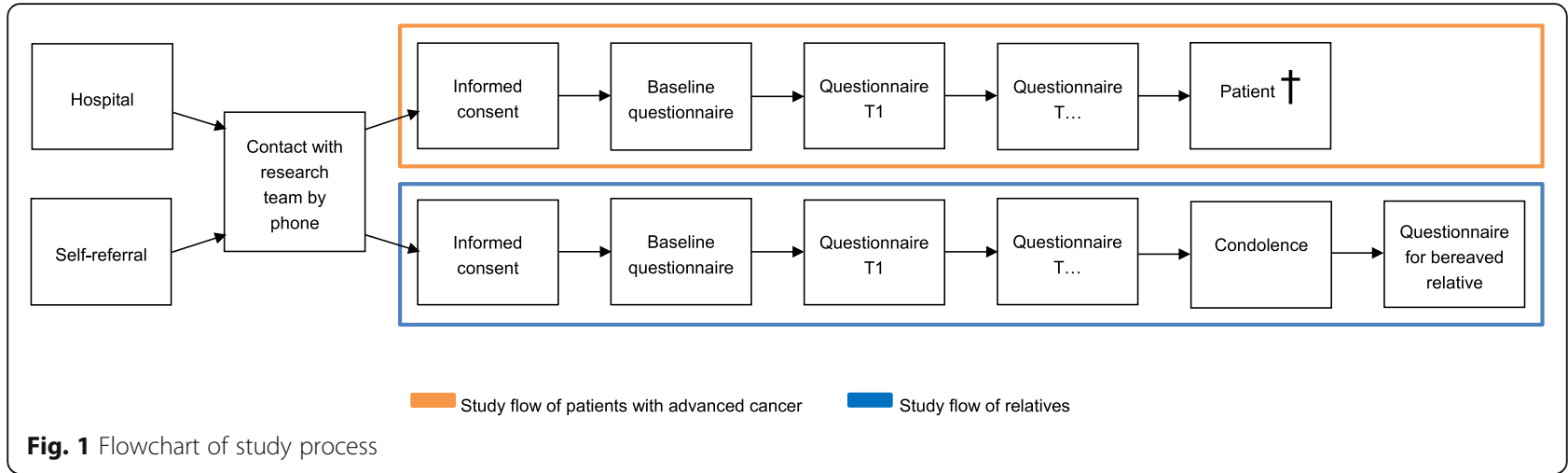

with care in the last phase of life of their loved one, QoL, the patient's quality of death, and post-bereavement needs and support.

\section{Questionnaires}

A qualitative study was conducted (METC16.2050) to gather input from patients with advanced cancer and their relatives in the development of our questionnaire [15] (Van Roij et al: Shared persepctives of patients with advanced cancer and their informal caregivers on essential aspects of health care: a qualitative study, submitted). Participants of the focus groups and interviews shared their experiences regarding QoC and QoL, which helped us identify relevant themes for this cohort study. Therefore, the questionnaires involve many topics related to QoC and QoL that were raised by patients with advanced cancer and relatives themselves. Additionally, a systematic literature review was conducted to identify suitable and valid measurement instruments to use in our study [16]. Furthermore, the approved Dutch Quality framework regarding palliative care [17] has also been taken into account while selecting relevant measurement instruments for the eQuiPe study to maximize the comparability of our results. Subsequently, socio-demographic variables such as marital status, ethnicity, educational level, and religion were self-administered and added to the questionnaires. Table 2 provides an overview of all measurement instruments included in the study.

The questionnaires were tested on completion time, appropriateness, and burden in a pilot study $(n=31)$ among patients with advanced cancer and relatives. The pilot consisted of the 'think-aloud' method with six participants (two patients with advanced cancer, two relatives, and two bereaved relatives) and 15 participants gave postal feedback. Results of the pilot study indicated that the mean completion time for the most extensive questionnaire (baseline measurement for patients) was $38 \mathrm{~min}$ and completing the questionnaire was not experienced as a great burden, confrontational, incomprehensible, or inappropriate. Suggestions made by the participants of the pilot study were taken into account to further improve the questionnaire. Results from the pilot suggested that the questionnaire length is suitable for our study population. For patients who also participate in national tumor-specific cohort studies (PLCR C, POCOP, PACAP) [41], the questionnaires will be aligned and adjusted in order to decrease the response burden for participants.

\section{PROFILES and NCR}

PROFILES will be used for the logistics of the questionnaires. PROFILES is a registry for the study of the physical and psychosocial impact of cancer and its treatment from a dynamic, growing population-based cohort of people confronted with cancer. PROFILES follows the quality guidelines that are formulated in the 'Data Seal of Approval' document (www.datasealofapproval.org), developed by Data Archiving and Networked Services. The PROFILES registry is an ongoing data collection of patient reported outcomes within the sampling frame of the NCR and can be linked with clinical data of all individuals newly diagnosed with cancer in the Netherlands. For the eQuiPe study, sociodemographic and clinical data will be obtained from the NCR. Socio-demographic variables include date of birth, sex, and socio-economic status. Clinical data include cancer type, stage, and date of diagnosis.

\section{Study parameters \\ Main outcome}

The main outcome of this study is the experienced QoC and QoL in patients with advanced cancer and their relatives. This includes all domains of QoL such as physical, psychological, social, and spiritual wellbeing.

\section{Secondary outcomes}

Secondary outcomes in this study are health care needs, shared decision making, and health care consumption of patients and relatives. Furthermore, social support, resilience, body image, sexual wellbeing, illness perception, 
Table 2 Overview measurement instruments and times points at which the questionnaires are administered during the study

\begin{tabular}{|c|c|c|c|c|}
\hline Measurement & Measurement instrument & Baseline & $\begin{array}{l}\text { Follow-up } \\
\text { (every } 3 \text { months) }\end{array}$ & $\begin{array}{l}\text { After patients' } \\
\text { death }\end{array}$ \\
\hline
\end{tabular}

\section{Patients}

\section{Quality of care}

Health care consumption

Shared decision making

Health care needs

\section{Quality of life}

Spiritual wellbeing

Social support

Use of social network

Sexual health

Body image

Relationship satisfaction $^{a}$

Illness perception

Individual coping

Resilience

Dyadic coping ${ }^{a}$

Self-management

Depression

\section{Relatives}

Quality of care

Health care consumption

Health care needs

Evaluation of services

\section{Quality of life}

Sexual health

Social support

Personal self-care

Caregiver burden

Relationship satisfaction ${ }^{a}$

Individual coping

Resilience

Pre-death grief

Dyadic coping

Circumstances of death

Openness of communication about illness and death

Impact of death
QLQ-IN-PATSAT32 [18], items CQ-index [19] items based on Dutch Quality framework Palliative Care [17]

Self-administered items

CPS [20], DEPS [21], Self-administered items

PNPC-sv patient form [22]

EORTC QLQ-C30 [23]

FACIT-sp [24]

FACT-G scale [25]

Self-administered item

single items EORTC

BIS [26]

Relationship ladder of the DAS [27]

BIP [28]

Brief COPE Inventory [29]

Connor-Davidson Resilience Scale [30]

$\mathrm{DCl}$ [31]

HeiQ [32]

HADS depression scale [33]

INPATSAT32 [18], CQ-index [19], items based on Dutch Quality framework

Palliative Care [17]

Self-administered items

PNPC-sv caregiver form [22]

VOICES-SF [34], items based on Dutch Quality framework Palliative Care [17]

EORTC QLQ-C30 items [23]

single items EORTC

FACT-G scale [25]

Personal Self-Care subscale of the SCPS [35]

ZARIT-12 [36], SRB [37]

Relationship ladder from the DAS [27]

brief COPE Inventory [29]

Connor-Davidson Resilience Scale [30]

Pre-death grief [38]

DCl [31]

Self-administered items

CCID [39]

IES [40]

X $\quad x$

$X$

$x$

$x$

$x$

$X$

$-$

X

$x$

$x$

X

$X$

$X$

$-$

$-$

$x$

$x$

$x$

- $-\quad$ X

$x \quad x \quad x$

$x \quad x$

$x \quad x \quad x$

$x \quad x \quad x$

$x \quad x$

$x \quad x$

$x$

$x \quad x$

$x \quad x$

$x$

$X$

$x$

Abbreviations: BIP Brief illness perception, BIS Body image scale, BMI Body mass index, CCID Caregiver's communication with the patient about illness and death, CPS Control preferences scale, CQ-index Consumer quality index, DAS Dyadic adjustment scale, DCI Dyadic coping inventory, DEPS Decisionmaking participation self-efficacy scale, EORTC QLQ-C30 European organization for research and treatment of cancer quality of life questionnaire core 30 items, FACIT-sp Functional assessment of chronic illness therapy spiritual well-being, FACT-G Functional assessment of cancer therapy general, HADS Hospital anxiety and depression scale, HeiQ Health education impact questionnaire, IES Impact of event scale, INPATSAT32 In-patient satisfaction with care measure 32 items, PNPC-sv Problems and needs in palliative care short form, SCPS Self care practices scale, SRB Self-rated burden scale, VOICES-SF Views of informal carers' evaluation of services short form, ZARIT-12 Zarit Burden

a only provided to those patients and relatives with a partner 
individual coping, self-management, depression and use of social networks are measured (Table 2). Relatives will also receive questions on caregiver burden and personal self-care. For patients and relatives with a partner, also relationship satisfaction and dyadic coping will be assessed. In bereaved relatives, health care services in the last days of the patients' life and aftercare will be evaluated. Furthermore, circumstances and impact of the patient's death and the communication between relative and patient about illness and death are assessed.

\section{Statistical analysis}

We aim for a large study population of approximately 1500 patients with advanced cancer and 1000 relatives. Including a large group of patients and relatives is necessary to assess the QoC and QoL of these participants at different time points in the palliative care trajectory and its course. A study sample of this size enables us to perform subgroup analyses, for example per age group, primary tumor site, cancer treatment, diagnosis, sex, and geographical region. Also, high dropout and lower response rates due to disease-related characteristics of our study population have to be taken into account. Due to the nature of this observational study, no sample size calculations haven been performed but the number of patients are based on annual incidence of advanced cancer in the Netherlands as recorded in the NCR.

All statistical analysis will be performed using statistical packages STATA version 16. For all analyses a two-sided significance level of $p<0.05$ will be used. Descriptive statistics (frequencies, median, mean) will be used to analyze the experienced QoC, QoL, healthcare use, advance care planning, symptom burden of patients and relatives. Further, univariate analyses will be used to analyze the crude differences between subgroups regarding QoC or QoL using parametric tests, provided that the assumptions of these tests are met. If not, non-parametric tests will be used. When testing differences between subgroups, we will adjust for confounders which are theoretically relevant and statistically associated with the outcome variable of interest. Additionally, multi-level analyses will be used to analyze the primary and secondary outcomes over time.

\section{Dissemination}

The funding party (Roparun) and accredited METC of this study will receive a final report of the study with recommendations. Furthermore, results of this study will be published in multiple peer-reviewed publications in scientific journals. The study aims to provide an (inter-)nationally accessible source of data. These data will be available for (internal) auditing and policy making, as all data of the PROFILES registry. PROFILES will perform first analyses on the data to check the quality and validity. After this process, the data will be freely available for research questions from other noncommercial groups in the Netherlands and abroad, subject to study question, privacy, and confidentiality restrictions, and registration [14].

\section{Discussion}

The eQuiPe study aims to gain more insight into the experienced QoC and QoL in patients with advanced cancer and their relatives. Results from the study will raise awareness regarding the poor prognosis of advanced cancer and palliative care needs of patients and their relatives. Furthermore, the eQuiPe study is a unique national project in which many health care professionals unite to gain a deeper understanding of experienced palliative care. Results from this study will inform us on how to further improve palliative care in the Netherlands for patients with advanced cancer and their relatives.

This prospective longitudinal observational cohort study has several strengths. First, we will include about 1500 patients with solid metastasized tumor of any type and approximately 1000 relatives. Due to this large study population it is possible to assess the experienced QoC and QoL of patients and relatives at different time points in the palliative care trajectory. Moreover, this large study sample also enables us to perform subgroup analyses, for example per age group, primary tumor site, cancer treatment, diagnosis, sex, and geographical region. Second, both advanced cancer patients and their relatives are included. Our explorative qualitative study on QoL in patients with advanced cancer and their relatives, as preparation for this current study, showed that advanced cancer has a substantial impact on social engagement, social identity, and social networks for both patients and relatives [15]. Therefore, in order to improve palliative care it is of essence to focus on relatives to really comprehend their experiences. The inclusion of patients and relatives simultaneously also gives rise to the opportunity to assess them as a dyad, thus taking the interaction between patients and relatives into account. Third, the eQuiPe study is a longitudinal study. In contrast to the majority of the conducted studies on palliative care, patients and relatives will now be followed over time, from inclusion until death and thereafter for the relatives. This will provide insight in changes in their experiences over time which are currently only limitedly known to us. Fourth, our approach of including patients and relatives is highly personal. All patients and relatives will be contacted by phone by the research team to discuss participation. Participants will also be contacted by phone when they have not completed one of the questionnaires. At last, this is a national study. Already 40 of the 80 hospitals in the Netherlands are collaborating with the eQuiPe study, covering a range of academic, 
teaching and general hospitals and the study has a good geographic spread. Therefore, the conclusions that will follow from the results of the eQuiPe study are likely to be representative for the Netherlands and generalizable for different regions and care settings.

We also expect to encounter some challenges and potential limitations in the eQuiPe study. Firstly, selection bias cannot be ruled out because patients with a higher QoL may be more likely to participate in the study compared to patients with a lower QoL [42]. Health care professionals may contribute to this bias by only asking patients with a higher QoL to participate in our study but also patients that are self-referred may be more inclined to participate when having a higher QoL. For this reason, we emphasize during the initiation visit that professionals can ask all patients with metastasized disease who fulfill the inclusion criteria. Furthermore, attrition may occur because the condition of the patient might worsen over time such that further participation becomes impossible. As a result, information on the last months of life may be limited. Besides that, the life expectancy of patients varies depending on primary tumor type, which means that some patients will live for 3 months while others may live much longer. In an attempt to reduce this variation and overrepresentation of patients with advanced cancer with a relatively good prognosis, additional inclusion criteria are required for patients with breast cancer and with prostate cancer. A possible alternative for the starting point we considered was the surprise question: "Would I be surprised if this patient died in the next 12 months?". However, according to the review of Downar at al [43]., the surprise question seems to be a poor to modestly predictive tool for patients with a near death. Therefore, we opted for an objective measure, namely having metastatic cancer. Another possible limitation is the length of the questionnaires. Due to the length, the workload for participants can become high, which can lead to a higher drop-out, especially in patients experiencing more symptoms from their disease. However, a meta-analysis showed no clear indication that response rates are attributable to the length of questionnaires [44]. A possible solution could be to use computer adaptive testing, but when using computer adaptive testing, it is of essence that all participants use the same mode (i.e., a computer) to answer the questionnaires, otherwise scores are not comparable. We wanted participants to have the option to complete questionnaires on paper as this remains a commonly preferred mode of participation [45]. At last, the clinical data are collected by the NCR, but these are mostly based on initial diagnosis and treatment. Therefore, some clinical data, for example information about treatment in the complete palliative care trajectory, will be collected via the questionnaires. However, some patients may not be fully aware of the specifics of the treatment they receive, hence, information regarding these clinical data may be incomplete.

\section{Abbreviations}

QoC: Quality of care; QoL: Quality of life; NCR: National Cancer Registry; PI: Principle investigator; PROFILES: Patient Reported Outcomes Following Initial treatment and Long term Evaluation of Survivorship

\section{Acknowledgements}

We thank all participating hospitals for their effort and support regarding this study, especially nurses and research staff who are essential for successful implementing the study. Most important, we thank all patients and relatives who will share their experiences by completing questionnaires in this phase of their life.

Collaborators: eQuiPe study group

The eQuiPe study group currently exists of the following hospitals in the Netherlands: Maxima Medical Centre, Velhoven, the Netherlands (Art

Vreugdenhil and Maggy Youssef-ELSoud), Catharina Hospital, Eindhoven, the Netherlands (Geert-Jan Creemers and Ben van den Borne), Hospital Gelderse Vallei, Ede, the Netherlands (Wouter de Jong and Arnold Baars), Maastricht University Medical Centre, Maastricht, the Netherlands (Marieke van den Beuken - van Everdingen), Radboud Medical Centre, Nijmegen, the Netherlands (Evelien Kuip), Maas Hospital Pantein, Boxmeer, the Netherlands (René Bunnik), Northwest Clinics, Alkmaar/Den Helder, the Netherlands (Mathijs Hendriks), Canisius Wilhelmina Hospital, Nijmegen, the Netherlands (Caroline Mandigers and Jean-Paul van Basten), Viecuri Hospital, Venlo, the Netherlands (Vivian van Kampen - van den Boogaart and Philo Werner), Erasmus Medical Centre, Rotterdam, the Netherlands (Lia van Zuylen), University Medical Centre Utrecht, Utrecht, the Netherlands (Alexander de Graeff and Anne van Lindert), Slotervaart Hospital, Amsterdam, the Netherlands (Marcel Soesan), St. Antonius Hospital, Utrecht, the Netherlands (Jarmo Hunting), St. Anna Hospital, Geldrop, the Netherlands (Arno Smals, Linda van de Winkel, Gerben Stege, and Liese Verhaert), St. Jans Gasthuis Weert, Weert, the Netherlands (Natascha Peters), Elkerliek Hospital, Helmond, the Netherlands (Manon Pepels), Jeroen Bosch Hospital, 's Hertogenbosch, the Netherlands (Tineke Smilde), Wilhelmina Hospital Assen, Assen, the Netherlands (Peter Nieboer and Sander de Hosson), Laurentius Hospital, Roermond, the Netherlands (Marien den Boer and Cordula Pitz) Rivierenland Hospital, Tiel, the Netherlands (Rick Heyne and Manuel Tjin-A-Ton), Maasstad Hospital, Rotterdam, the Netherlands (Annemieke van der Padt - Pruijsten and Paul van den Berg), Spaarne Gasthuis, Hoofddorp, the Netherlands (Frans Krouwels), Diakonessehuis, Utrecht, the Netherlands (Lobke van LeeuwenSnoeks and Femke van der Meer), Bernhoven, Uden, the Netherlands (Allert Vos), Antonius Hospital, Sneek, the Netherlands (Gerrit Jan Veldhuis), Ommelander Hospital, Groningen, the Netherlands (Boelo Poppema), Ikazia Hospital, Rotterdam, the Netherlands (Martine Thijs-Visser and Roxane HellerBaan), Dijklander Hospital, Hoorn/Purmerend, the Netherlands (Marjolein van Laren and Karen Maassen van den Brink), Treant Zorggroep, Emmen, the Netherlands (Gea Douma), Elisabeth-TweeSteden Hospital, Tilburg, the Netherlands (Jeroen Kloover), Flevo Hospital, Almere, the Netherlands (Dirkje Sommeijer and Lemke Pronk), Admiraal de Ruyter Hospital, Goes, the Netherlands (Ellen Janssens - van Vliet), Antoni van Leeuwenhoek hospital, Amsterdam, the Netherlands (Lilly-Ann van der Velden and Emma Hafkamp), Haga hospital, Den Haag, the Netherlands (Henk Codrington), Zaans Medical Centre, the Netherlands (Svitlana Tarasevych and Aart van Bochove),

Spijkenisse Medical Centre, Spijkenisse, the Netherlands (Annemieke van der Padt - Pruijsten), Tjongerschans ziekenhuis, Heerenveen, The Netherlands (Jaap de Boer), Geraldine Vink (Prospective Dutch ColoRectal Cancer cohort $(\mathrm{PLCRC})$ ).

\section{Authors' contributions}

$L P, N R, L B, H F$, and JR were involved in designing the study. JR and $L H$ drafted the manuscript. All authors reviewed the manuscript and agreed with the final version.

\section{Funding}

The eQuiPe study is funded by the Roparun Foundation. This funding source had no role in the design of this study and will not have any role during its execution, analyses, interpretation of the data, or decision to submit results.

\section{Availability of data and materials}

Data sharing is not applicable to this article as no new data were created or analyzed in this study. 


\section{Ethics approval and consent to participate}

The study will be conducted according to the declaration of Helsinki. The study protocol is reviewed by the Medical Ethical Committee of the Dutch Cancer Institute (NKI) in Amsterdam, the Netherlands (METC17.1491). The METC has exempted this observational research from ethical review, accordingly to the Dutch Medical Research Involving Human Subjects Act (WMO). Furthermore, in data collection and analyses procedures, the rules of Dutch Personal Data Protection Act and the General Data Protection Regulation (GDPR) will be followed. In all collaborating hospitals, local scientific committees, if present, will be contacted to get local approval and a check for competitive studies will be done in consultation with the concerning department. Written informed consent will be obtained from all study participants.

\section{Consent for publication}

Not applicable.

\section{Competing interests}

The authors declare that they have no competing interests.

\section{Author details}

${ }^{1}$ The Netherlands Comprehensive Cancer Organization, PO Box 19079, 3501 DB Utrecht, The Netherlands. ${ }^{2}$ CoRPS - Center of Research on Psychology in Somatic Diseases, Department of Medical and Clinical Psychology, Tilburg University, Tilburg, The Netherlands. ${ }^{3}$ Netherlands Association for Palliative Care (PZNL), Utrecht, the Netherlands. ${ }^{4}$ Department of Psychology, Pantein, Boxmeer, The Netherlands. ${ }^{5}$ Department of Internal Medicine, St. Jans Gasthuis, Weert, The Netherlands. ${ }^{6}$ Department of Medical Oncology, Maxima Medical Centre, Eindhoven, The Netherlands. ${ }^{7}$ Division of Psychosocial Research and Epidemiology, The Netherlands Cancer Institute, Amsterdam, The Netherlands.

Received: 19 August 2019 Accepted: 28 August 2020

Published online: 09 September 2020

\section{References}

1. CBS. 2017. https://www.cbs.nl/nl-nl/nieuws/2018/28/kanker-oorzaak-bij-31procent-van-de-sterfgevallen. Last checked April 24th 2019.

2. CBS. 2014. https://www.cbs.nl/nl-nl/nieuws/2014/50/de-meeste-mensensterven-aan-kanker-en-hart-en-vaatziekten. Last checked April 24th 2019.

3. Murray SA, Kendall M, Boyd K, Sheikh A. Illness trajectories and palliative care. BMJ. 2005;330(7498):1007-11.

4. WHO. Definition palliative care. 2002. http://www.hoint/cancer/palliative/ definition/en/. Accessed 23 Nov 2016.

5. Temel JS, Greer JA, Muzikansky A, Gallagher ER, Admane S, Jackson VA, et al. Early palliative care for patients with metastatic non-small-cell lung cancer N Engl J Med. 2010;363(8):733-42.

6. Haun MW, Estel S, Rucker G, Friederich HC, Villalobos M, Thomas M, et al. Early palliative care for adults with advanced cancer. Cochrane Database Syst Rev. 2017:6:CD011129.

7. Hui D, Kim YJ, Park JC, Zhang Y, Strasser F, Cherny N, et al. Integration of oncology and palliative care: a systematic review. Oncologist. 2015;20(1):77-83.

8. Kaasa S, Loge JH, Aapro M, Albreht T, Anderson R, Bruera E, et al. Integration of oncology and palliative care: a lancet oncology commission. Lancet Oncol. 2018;19(11):e588-653.

9. Woitha K, Garralda E, Martin-Moreno JM, Clark D, Centeno C. Ranking of palliative care development in the countries of the European Union. J Pain Symptom Manag. 2016:52(3):370-7.

10. Engel M, Brinkman-Stoppelenburg A, Nieboer D, van der Heide A. Satisfaction with care of hospitalised patients with advanced cancer in the Netherlands. Eur J Cancer Care (Engl). 2018;27(5):e12874.

11. Dutch federation of Cancer Patients Organisations (NFK). Als je niet meer beter wordt wat heb je dan nodig? 2018. https://nfk.nl/resultaten/als-je-nietmeer-beter-wordt-wat-heb-je-dan-nodig. Accessed 15 May 2019.

12. Raijmakers NJFA. Kwaliteit van palliatieve zorg door de ogen van patiënten en nabestaanden. Tijdschrift over Kwaliteit en Veiligheid in Zorg. 2015;25(3):8-11.

13. Witkamp FE, van Zuylen L, Borsboom G, van der Rijt CC, van der Heide A. Dying in the hospital: what happens and what matters, according to bereaved relatives. J Pain Symptom Manag. 2015;49(2):203-13.
14. van de Poll-Franse LV, Horevoorts N, van Eenbergen M, Denollet J, Roukema JA, Aaronson NK, et al. The patient reported outcomes following initial treatment and long term evaluation of survivorship registry: scope, rationale and design of an infrastructure for the study of physical and psychosocial outcomes in cancer survivorship cohorts. Eur J Cancer. 2011;47(14):2188-94.

15. van Roij J, Brom L, Youssef-El Soud M, van de Poll-Franse L, Raijmakers NJH. Social consequences of advanced cancer in patients and their informal caregivers: a qualitative study. Support Care Cancer. 2019;27(4):1187-95.

16. van Roij J, Fransen $\mathrm{H}$, van de Poll-Franse L, Zijlstra M, Raijmakers N. Measuring health-related quality of life in patients with advanced cancer: a systematic review of self-administered measurement instruments. Qual Life Res. 2018;27(8):1937-55.

17. Palliactief TNCCOI. Kwaliteitskader palliatieve zorg Nederland. 2017.

18. Bredart A, Bottomley A, Blazeby JM, Conroy T, Coens C, D'Haese S, et al. An international prospective study of the EORTC cancer in-patient satisfaction with care measure (EORTC IN-PATSAT32). Eur J Cancer. 2005;41(14):2120-31.

19. Sixma HHM, Boer D, Delnoij D. Handboek CQI Metingen: richtlijnen en voorschriften voor metingen met een CQI meetinstrument 2008; 2008.

20. Degner LF, Sloan JA, Venkatesh P. The control preferences scale. Can J Nurs Res. 1997;29(3):21-43.

21. Arora NK, Weaver KE, Clayman ML, Oakley-Girvan I, Potosky AL. Physicians' decision-making style and psychosocial outcomes among cancer survivors. Patient Educ Couns. 2009;77(3):404-12.

22. Osse BH, Vernooij MJ, Schade E, Grol RP. Towards a new clinical tool for needs assessment in the palliative care of cancer patients: the PNPC instrument. J Pain Symptom Manag. 2004;28(4):329-41.

23. Aaronson NK, Ahmedzai S, Bergman B, Bullinger M, Cull A, Duez NJ, et al. The European Organization for Research and Treatment of Cancer QLQ-C30: a quality-of-life instrument for use in international clinical trials in oncology. J Natl Cancer Inst. 1993;85(5):365-76.

24. Peterman AH, Fitchett G, Brady MJ, Hernandez L, Cella D. Measuring spiritual well-being in people with cancer: the functional assessment of chronic illness therapy--spiritual well-being scale (FACIT-Sp). Ann Behav Med. 2002; 24(1):49-58.

25. Cella DF, Tulsky DS, Gray G, Sarafian B, Linn E, Bonomi A, et al. The functional assessment of cancer therapy scale: development and validation of the general measure. J Clin Oncol. 1993;11(3):570-9.

26. Hopwood P, Fletcher I, Lee A, Al Ghazal S. A body image scale for use with cancer patients. Eur J Cancer. 2001;37(2):189-97.

27. Spanier GB. Measuring dyadic adjustment: new scales for assessing the quality of marriage and similar dyads. J Marriage Fam. 1976;38:15-28.

28. Weinman JPK, Moss-Morris R, Horne R. The Illness Perception Questionnaire: a new method for assessing the cognitive representation of illness. Psychol Health. 1996;11:431-45.

29. Carver CS. You want to measure coping but your protocol's too long: consider the brief COPE. Int J Behav Med. 1997;4(1):92-100.

30. Vaishnavi S, Connor K, Davidson JR. An abbreviated version of the ConnorDavidson Resilience Scale (CD-RISC), the CD-RISC2: psychometric properties and applications in psychopharmacological trials. Psychiatry Res. 2007; 152(2-3):293-7.

31. Bodenmann G. Dyadisches Coping Inventar: Testmanual [Dyadic coping inventory: testmanual]. Bern: Huber; 2008.

32. Osborne $\mathrm{RH}$, Elsworth $\mathrm{GR}$, Whitfield $\mathrm{K}$. The health education impact questionnaire (heiQ): an outcomes and evaluation measure for patient education and self-management interventions for people with chronic conditions. Patient Educ Couns. 2007;66(2):192-201.

33. Zigmond AS, Snaith RP. The hospital anxiety and depression scale. Acta Psychiatr Scand. 1983;67(6):361-70.

34. Hunt KJ, Richardson A, Darlington AE, Addington-Hall JM. Developing the methods and questionnaire (VOICES-SF) for a national retrospective mortality follow-back survey of palliative and end-of-life care in England. BMJ Support Palliat Care. 2019;9(1):e5.

35. Lee JJ, Bride B, Miller SE. Development and initial validation of the self-care practices scale (SCPS). In: Poster session presented at the meeting of the Society for Social Work and Research, Washington, DC; 2016.

36. Bedard M, Molloy DW, Squire L, Dubois S, Lever JA, O'Donnell M. The Zarit burden interview: a new short version and screening version. Gerontologist. 2001:41(5):652-7.

37. van Exel NJ, Scholte op Reimer WJ, Brouwer WB, van den Berg B, Koopmanschap MA, van den Bos GA. Instruments for assessing the burden of informal caregiving for stroke patients in clinical practice: a 
comparison of CSI, CRA, SCQ and self-rated burden. Clin Rehabil. 2004; 18(2):203-14.

38. van Doorn C, Kasl SV, Beery LC, Jacobs SC, Prigerson HG. The influence of marital quality and attachment styles on traumatic grief and depressive symptoms. J Nerv Ment Dis. 1998;186(9):566-73.

39. Mesters I, van den Borne H, McCormick L, Pruyn J, de Boer M, Imbos T. Openness to discuss cancer in the nuclear family: scale, development, and validation. Psychosom Med. 1997;59(3):269-79.

40. Horowitz M, Wilner N, Alvarez W. Impact of event scale: a measure of subjective stress. Psychosom Med. 1979;41(3):209-18.

41. Coebergh van den Braak RRJ, van Rijssen LB, van Kleef JJ, Vink GR, Berbee $M$, van Berge Henegouwen Ml, et al. Nationwide comprehensive gastrointestinal cancer cohorts: the 3P initiative. Acta Oncol. 2018;57(2):195-202.

42. de Rooij BH, Ezendam NPM, Mols F, Vissers PAJ, Thong MSY, Vlooswijk CCP, et al. Cancer survivors not participating in observational patient-reported outcome studies have a lower survival compared to participants: the population-based PROFILES registry. Qual Life Res. 2018:27(12):3313-24.

43. Downar J, Goldman R, Pinto R, Englesakis M, Adhikari NK. The "surprise question" for predicting death in seriously ill patients: a systematic review and meta-analysis. CMAJ. 2017;189(13):E484-E93.

44. Rolstad S, Adler J, Ryden A. Response burden and questionnaire length: is shorter better? A review and meta-analysis. Value Health. 2011;14(8):1101-8.

45. Horevoorts NJ, Vissers PA, Mols F, Thong MS, van de Poll-Franse LV. Response rates for patient-reported outcomes using web-based versus paper questionnaires: comparison of two invitational methods in older colorectal cancer patients. J Med Internet Res. 2015;17(5):e111.

\section{Publisher's Note}

Springer Nature remains neutral with regard to jurisdictional claims in published maps and institutional affiliations.

Ready to submit your research? Choose BMC and benefit from:

- fast, convenient online submission

- thorough peer review by experienced researchers in your field

- rapid publication on acceptance

- support for research data, including large and complex data types

- gold Open Access which fosters wider collaboration and increased citations

- maximum visibility for your research: over $100 \mathrm{M}$ website views per year

At $\mathrm{BMC}$, research is always in progress.

Learn more biomedcentral.com/submissions 